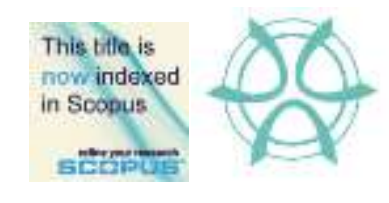

\title{
EXPLORING THE THEORY PLANNED BEHAVIOUR TO DERIVE THE FACTORS OF HUMAN BEHAVIOUR FOR DOMESTIC WASTE RECYCLING
}

\author{
Nurul Rif'ah Afiqah Abd Rauf ${ }^{1}$, Hamizah Yakob ${ }^{2}$, Yusfida Ayu Abdullah ${ }^{3}$, Oliver \\ Ling Hoon Leh ${ }^{4}$, Marlyana Azyyati Marzukhi ${ }^{5}$ and Raja Norashekin Raja \\ Othman $^{6}$ \\ 1,2,3,4,5,6 Faculty of Architecture, Planning, and Surveying, \\ ${ }^{2,3}$ Responsive Environmental Development (RED) Research Group, \\ UNIVERSITI TEKNOLOGI MARA (UiTM)
}

\begin{abstract}
Malaysia is experiencing waste disposal management issues involving the lack of recycling practices among human behaviour, the absence of domestic waste recycling mechanisms, and poor enforcement for recycling activities. Previous studies revealed that households generate domestic waste hence requires changes in domestic waste management. This paper aims to establish the conceptual framework of solid waste recycling practice by employing the Theory of Planned Behaviour (TPB). Content analysis was employed to verify the trends of research in the related topic. From prior related studies, a variety of approaches based on the TPB model were examined. Results demonstrated that many factors influence the household's behaviour in domestic waste recycling using the TPB model. The outcome of this study was a conceptual framework in determining the factors of human behaviour in domestic waste recycling. The framework can therefore be a mechanism for authority in managing domestic waste.
\end{abstract}

Keywords: Human Behaviour; Domestic Waste; Recycling; Theory of Planned Behaviour

\footnotetext{
${ }^{3}$ Associate Professor at University Teknologi Mara. Email: yusfida@uitm.edu.my
} 


\section{INTRODUCTION}

Tolinski (2012) and Bakar et al. (2017) consider ecological sustainability ideas are linked with "nature and technology, where the people are aware of the importance of protecting their environment despite their actual behaviours. According to Sachs (2015), acting and conducting activities to safeguard the environment is part of environmental protection. Consequently, the Malaysian government has raised concerns regarding environmental protection and the importance of waste disposal management due to a lack of landfill space, increased waste management costs, and inefficient recycling management (Eusuf et al., 2011). Moreover, Mokhtar et al. (2013) claimed that Malaysia collected 33,000 tons of waste each day in 2013, an increased volume from 19,000 tons in 2005 , thereby raising the cost of waste management with a further absence of a proper mechanism that addresses the poor recycling of domestic waste. Even though Malaysia's National Solid Waste Department was established in 2007, Jereme et al. (2015) noted that further issue arises due to the unregulated waste service fees because it was no longer within the control of local authorities but rather of waste management corporations. Meanwhile, recycling has been advocated since the $1990 \mathrm{~s}$; nonetheless, just $5 \%$ of Malaysian waste has been recycled (Aini et al., 2002) due to inadequate planning and a lack of public participation.

\section{RECYCLING AND THE THEORY OF PLANNED BEHAVIOUR (TPB)}

The attitude of recycling can be characterised as conclusive behaviours, whereby the number of people who never recycle and always recycle is found alike. Contrarily, only a few usually recycle or hardly recycle (Barr, 2007). Moreover, people will only recycle when forced to or given the relevant opportunity (Tabernero et al., 2015). In the context of recycling behaviour, Teo (2016) claims that there have been initiatives in psycho-social aspects that prove to be successful. Therefore, this study addresses how individuals' understanding of attitudes and behaviour influences can significantly highlight behavioural aspects that significantly impact recycling practices. According to Karim et al. (2013), human behaviours are often directed by three aspects; 1) the perceptions of the expected outcome (attitude); 2) expectations of normative beliefs and the desire to meet those expectations (subjective), and 3) views on the factors that can influence behaviour (behavioural control). Verdugo (2012) opined that Malaysians would recycle if there were favourable opportunities, recycling initiatives, and incentives, which would drive the people to recycle. Meanwhile, contentment is seen as linking factors like the performance of the recycling services provided, including the duration, approachable and value of the action 
Nurul Rif'ah Afiqah Abd Rauf, Hamizah Yakob, Yusfida Ayu Abdullah, Oliver Ling Hoon Leh, Marlyana Azyyati Marzukhi and Raja Norashekin Raja Othman

Exploring the Theory Planned Behaviour to Derive the Factors of Human Behaviour for Domestic Waste Recycling

(Tabernero et al., 2015). Nevertheless, demographic patterns and societal standards are also relevant, as are reward programs, strategies or how mature the recycling community is. Tabernero et al. (2015) discovered that communities with stronger motivation and understanding have healthier recycling habits. Chen \& Lee (2020) also agreed that the people staying in larger cities and communities tend to recycle more than those in smaller groups and towns. Additionally, a good recycling motivation will help to forecast recycling behaviours (Aini, 2002).

Ajzen put forward the Theory of Planned Behaviour (TPB) in 1991. The theory was created to study and describe human behaviour by structuring the idea into four (4) subjects; intentions, stance toward the behaviour, subjective norms and perceived behavioural control. A significant factor in the TPB is the individual's purpose of performing an action. For instance, the stronger the intent to engage in recycling behaviour, the more likely it is to achieve that behaviour (Ajzen, 1991). The first structure of the model is the 'intention', which assumes to obtain the impulse that affects behaviour, i.e., signs of how complex people try and how much they struggle to perform recycling practice. The second structure requires behavioural beliefs and actions. It is an attitude towards an individual's action with a specific behaviour, whether desirable or undesirable.

Meanwhile, the third structure is the subjective norm that constitutes social pressure to recycle. As a result, the personal standard is formed by combining moral ideas and a desire to recycle. Alleged behavioural control is widely regarded as an essential attitude in TPB. It relates to people's understanding of how complicated or straightforward the action of recycling is to carry out. Therefore, this paper aims to explore the application of the TPB in deriving the factors of human behaviour that impacts domestic waste recycling.

\section{METHODOLOGY}

This research employed the Content Analysis method, using the Atlas.ti software to examine past literature on waste disposal management and formulate the conceptual framework of human behavioural factors that impact domestic waste recycling. The application of scoping study (using SCOPUS and WoS indexed publications) consists of five (5) stages of data extraction in the literature search, as suggested by Arksey \& O'Malley (2005). The first stage of the process was to gather all past studies focusing on waste disposal management. A total of 181 related studies were collected spanning from 1991 until 2020. The second stage filters the literature based on their objectives that specifically concentrate on human behaviour and factors that will shape their attitude toward waste recycling. A snowballing technique was applied through the reference lists using the keywords "domestic waste AND recycling AND human behaviours AND households AND factors", scaling further 160 papers removal as they do not 
match the objective mentioned above. As a result, only 21 articles were considered for the final analysis. The third stage involves categorising the research selection, which confirmed the literature for review and references. The categorisation was divided into themes: human behaviour and attitudes toward recycling and factors influencing recycling behaviour. The fourth stage was to chart and group the human behaviour and factors using the TPB accordingly. Finally, the last stage was to formulate the conceptual framework by proposing an extended TPB model (Figure 1).

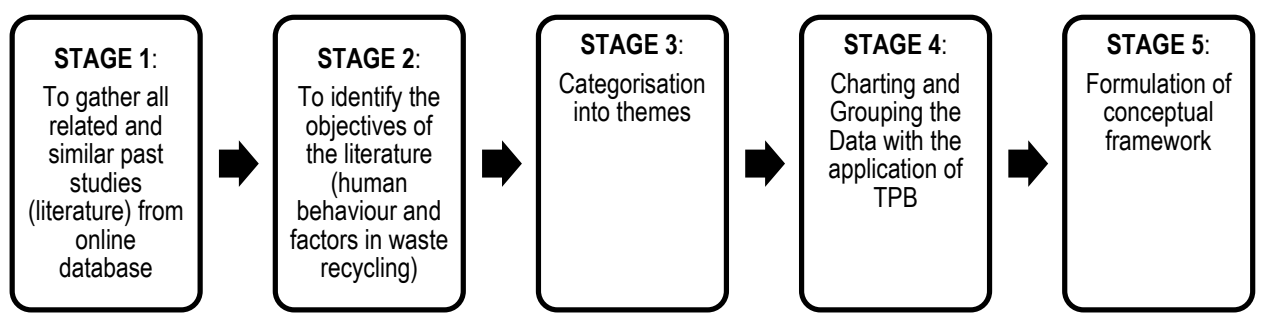

Figure 1: Scoping Study approach

The preliminary work conducted a detailed background study from previous similar literature to justify this study's need. The reviewing exercise included the online publications from 1991 to 2020 that specifically concentrate on recycling, the factors and indicators that include the TPB. Evidently, most literature had considered the TPB for their framework when discussing human behaviour. Ajzen (1991) used the TPB to forecast attitude in order to comprehend actual behaviour and concluded that the TPB is useful as a conceptual framework to study human recycling behaviour. Knickmeyer (2020) and Chen \& Lee (2019) applied the TPB in studying household waste segregation in terms of social factors. Meanwhile, the behaviour of adults towards e-waste recycling was studied by Kumar (2019). Other references using the TPB include associations of the determinant's variables (Strydom, 2018; Xu et al., 2017), an inquiry on behaviours in waste management by Ong et al. (2019), socio-demographic aspect to enhance waste management (Becker \& Lindhqvist, 2014), the motivation and inspiration to recycle (Miafodzyeva \& Brandt 2013), pro-environmental beliefs and attitude (Chu \& Chiu, 2003), the determinants of the desire for online recycling (Wang et al.), and household recycling and the effect of spatial factors (Toit et al., 2017). 
Nurul Rif'ah Afiqah Abd Rauf, Hamizah Yakob, Yusfida Ayu Abdullah, Oliver Ling Hoon Leh, Marlyana Azyyati Marzukhi and Raja Norashekin Raja Othman

Exploring the Theory Planned Behaviour to Derive the Factors of Human Behaviour for Domestic Waste

Recycling

\section{RESULTS AND DISCUSSION}

The research finds that a previous similar TPB Model in the literature applies to examine human behaviour using the Content Analysis Method. The following is a summary of the analysis findings.

The data collected from the twenty-one articles was thematically studied based on regions. In Asia, Chen \& Lee (2020) had investigated the effect of internal and external incentives of waste separation among residents' motivation in China and the importance of public policy on waste separation behaviour. Wang et al. (2019) applied an extended TPB theory in exploring erecycling by looking at the community's obligations to participate in online recycling efforts and investigate the contributing factors through a survey at a national level. In Singapore, Ong et al. (2019) used door-to-door surveys to compare and assess three (3) major hypotheses that explain domestic waste management behaviour, including socio-cultural, social-structural, and social psychology theories. Furthermore, Xu et al. (2017) studied key determinants influencing household waste separation intention and behaviour based on the TPB model using Systematic Sampling and Descriptive Analysis to understand the demographic characteristics factors. Chu \& Chiu (2003) analysed the roots of Taiwan's household waste recycling behaviour by employing an integrated model of the Theory of Reasoned Action (TRA) and found that TPB is more likely to be applied in studying human behaviour. Moreover, findings indicate recycling habits do not rely on incentives (Chen \& Lee, 2020). Nonetheless, economic variables, societal context and public knowledge might impact these practices (Wang et al., 2019; Ong et al., 2019). Also, moral responsibilities and values may impact human behaviour regarding environmental protection (Xu et al., 2017). Meanwhile, Chu \& Chiu (2003) exposed that TPB is more likely to be applied in studying human behaviour.

In other parts of the world, such as in Equestria, South Africa, Toit et al. (2017) conducted a similar TPB study, demonstrating the TPB's relevance in determining the recycling behaviour of residents living in townhouses. The findings demonstrated the significance of control factors at townhouses, which indicated a gap for further research that may incorporate other independent variables such as experience, ethics, situational features, and observed effects of recycling practices. The study's findings, which involved 1,250 townhouse units from a middle-income group, showed that everyone, including non-recyclers, was inclined to recycle. However, this finding contradicts Strydom's (2018) study, which found that many Africans were hesitant to recycle due to a lack of societal pressure and obligation.

Meanwhile, in Sweden, Miafodzyeva \& Brandt (2012) examined the Jarva city situated in the northwest of Stockholm discovered a connection in recycling between human behaviour and the determinants of recycling 
(motivation and intention). Nevertheless, there were no connections between human behaviour and other factors like cautions for the environmental state, identity of communities, provision of facilities, faith and belief in recycling, and socio-demographic factors . In 2014, Becker \& Lindhqvist (2014) found the correlation of income and age towards external conditions in recycling.

Barr (2007) applied the TPB model in the United Kingdom, which looked at households' behaviour in waste management from the environmental, situational, and psychological aspects, while Kumar (2019) undertook a behavioural study on e-waste among local university students. Kumar (2019) reported that perceived behaviour control, subjective norms, attitude, and selfresponsibility all influenced e-waste recycling.

Nonetheless, not all the twenty-one articles analysed employed the TPB model in their methodology. One example is a survey in Lithuania conducted by Miliute-Plepiene et al. (2016) that used the Schwartz Theory, which can also identify other human behavioural factors like techno-organisational, normative, and socio-demographic factors. The research only compared recycling behaviour at a preliminary stage of their study and reported that people were inclined to recycle because of existing recycling schemes. Although this study used a different theory model, it was still valuable for understanding the various components of recycling behaviour. Other research, such as a study conducted by Banerjee (2015) and Towolioe et al. (2016), focused on recycling terminology and definitions regarding the process and value of recycling that broadens the understanding of recycling. The activities and process of "Reduce, Reuse and Recycle" (3R) are vital since they can avoid increased illegal dumping and landfill areas. Instead, the $3 \mathrm{R}$ activity may produce a new item and encourage the practice of a greener economy.

Meanwhile, in Malaysia, Aini et al. (2002) examined the sustainability of the environment from recycling activities, while Fauziah \& Agamuthu (2012) reported that the government had enhanced its policy on waste management. Also, Jereme et al. (2014) studied the continuation of the discussion about waste management. The majority of findings suggest that a lack of planning and implementation hampers waste management in Malaysia according to the waste management hierarchy of reducing, reusing, and recycling (3R), as discussed above. Besides, most landfill areas are not adequately managed or maintained and are seldom assessed through the Environmental Impact Assessment or evaluated in site suitability. Moreover, Malaysia is still dealing with illegal waste disposal into rivers and streams, as well as continued unlawful dumping and the establishment of illegal landfills. In addition to poor recycling practices, many Malaysians have terrible waste management attitudes, for instance, discarding their trash along the roadsides just because the bins are defective. Unsurprisingly, according to a prior study by Abas (2014), Malaysian households do not practise 
Nurul Rif'ah Afiqah Abd Rauf, Hamizah Yakob, Yusfida Ayu Abdullah, Oliver Ling Hoon Leh, Marlyana Azyyati Marzukhi and Raja Norashekin Raja Othman

Exploring the Theory Planned Behaviour to Derive the Factors of Human Behaviour for Domestic Waste

Recycling

recyclables segregation. Therefore, according to Abas (2014), separating recyclable materials is often an unexpected and unplanned activity. He also mentioned that the incinerator programs in Malaysia are not fully practised. Nonetheless, Ali et al. (2017) found that waste minimisation activity among homes in Shah Alam, an urban area in Malaysia, was above average, implying that inhabitants were aware of recycling practices. Results, therefore, are highly dependent on gender, race, marital status and homeownership within the sociodemographic characteristics that affect the recycling behaviours.

Despite numerous behavioural theories, like Thomas and Sharp (2013) that focused more on psychological aspects such as attitudes and social norms in their recycling behaviour study, the TPB is the most frequently used theory to describe the pro-environmental purpose and behaviour (Al Mamun et al., 2018). Therefore, this study hinges human activities into three (3) beliefs by applying the TPB framework. It was constructed based on previous related studies by Ajzen (1991), Chu \& Chiu (2003), Miafodzyeva \& Brandt (2013), Becker \& Lindhqvist (2014), Miliute-Plepiene et al. (2016), Xu et al. (2017), Strydom (2018), Kumar, (2019), Wang et al., (2019) and Ong et al., (2019). The first belief posits that the possible outcome of explicit action and assessing the outcome (often known as behavioural belief). Secondly, the normative anticipation of other inspirations to meet such hope (known as normative beliefs). Finally, the lack or existence of other contributing factors may affect the performance of behaviour and alleged power, such as control beliefs. In short, if people have a better understanding of recycling, they would have the tendency and motivation to recycle.

This study then formulated a model that integrates the diverse factors of environmental behaviours from the previous studies whereby, it adopted the factors and designed a conceptual framework by assimilating the Theory of Planned Behaviour (TPB) and content analysis. The single model proposed is illustrated in Figure 2 below.

\section{An Extended Framework for the Theory of Planned Behaviour (TPB)}

The study developed a conceptual framework that incorporates human behaviours and factors that impact domestic waste recycling from the analysis and findings. Figure 2 below shows the network mapping as output from the analysis, which includes the lean coding based on the themes derived from the content analysis. It demonstrated the five (5) factors to measure the structure of the variables such as knowledge of recycling measures, spatial and physical characteristics, situational factors, behavioural or motivational measures, and social psychological measures correlated with socio-demographic variables and motivational factors. A few theories designed over the years by social 
psychologists were taken into consideration to examine, model, and forecast the human behaviour on recycling concerning behaviour factors and the determinants. The following section provides an overview of the proposed conceptual framework to the findings from the analysis.

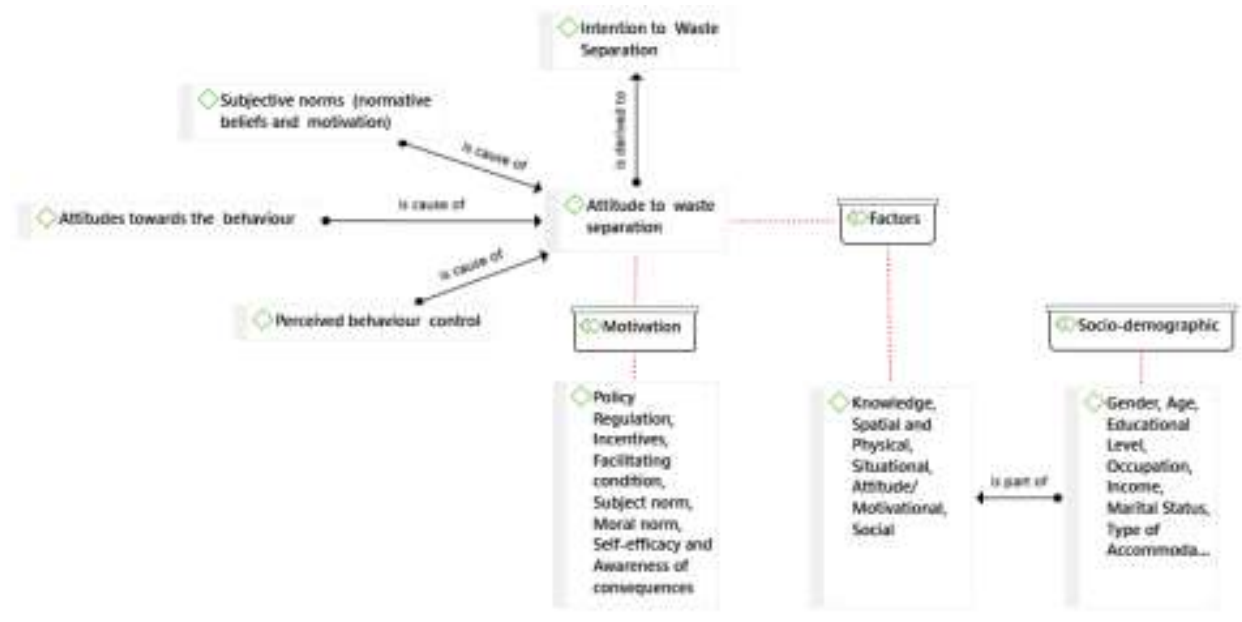

Figure 2: TPB Extended Model Framework

(Source: Adaptation from Ajzen (1991), Chu \& Chiu (2003), Miafodzyeva \& Brandt (2013), Becker \& Lindhqvist (2014), Miliute-Plepiene et al., (2016), Xu et al., (2017), Strydom, (2018), Kumar (2019), Wang et al. (2019), and Ong et al., (2019))

The conceptual framework had considered the socio-demographic factor whereby the association between the recycling system and users should still be considered. Concerning the framework, Becker \& Lindhqvist (2014) revealed that socio-demographic variables affect recycling rates and influence recycling behaviour. Those variables considered factors like education and occupation background, gender, age, income, and others.

Furthermore, the proposed conceptual framework incorporated the idea of Barr (2007) and Bakar et al. (2020), who emphasised that recycling knowledge is a necessary precondition for recycling behaviours. They emphasised the need for environmental awareness and understanding of recycling services. For example, recycled branding on products may confuse individuals with limited understanding and experience with recycling. Hence, the inadequate realisation of waste management practices amplifies information barriers such as language conflict reported by Miafodzyeva \& Brandt (2013) experienced by immigrants.

The framework also included spatial and physical factors, representing how town planners and architects designated the residence or township to help facilitate recycling in a residential area. Accessibility from collection sites or the roadside should be convenient, according to Toit et al. (2017), who advised that 
Nurul Rif'ah Afiqah Abd Rauf, Hamizah Yakob, Yusfida Ayu Abdullah, Oliver Ling Hoon Leh, Marlyana Azyyati Marzukhi and Raja Norashekin Raja Othman

Exploring the Theory Planned Behaviour to Derive the Factors of Human Behaviour for Domestic Waste

Recycling

recycling facilities per household should be provided. The perception of comfort depends on the person who is engaged in separating the waste system. This statement was supported by Miafodzyeva \& Brandt (2013) and Thomas \& Sharp (2013), who assessed that the lack of appropriate infrastructure could discourage the residents from recycling. Therefore, convenience is one of the most significant factors to encourage the public towards waste separation (Khalil et al., 2019). These factors impact the recycling attitude and the willingness to recycle, significantly affecting the overall environment. As stated in the Attitude Behaviour Context Theory, the willingness to recycle is very much related to factors like convenience, time and costs unless rewards or incentives are provided. Thus, attitude barriers influence the action to recycle (Kumar, 2019). Furthermore, sorting waste in separate containers demands high internal motivation and is influenced by social perceptions and attitudes. Hence, recycling as a behaviour carried out under favourable circumstances regularly may then become habitual.

\section{CONCLUSION}

This paper summarises the use of TPB in investigating human behaviour and factors relating to domestic waste recycling. Results demonstrated that by applying the TPB model, domestic waste recycling practice could be developed by extracting the factors influencing household behaviour towards domestic waste recycling and management. The framework indicated the factors like knowledge, spatial and physical planning, situational factors, behavioural or motivational measures, and social psychological measures to determine the household's behaviours. Therefore, this conceptual framework can be a mechanism for domestic waste management planning and be applied by the managing authority. Nevertheless, this research focused primarily on qualitative analysis. Hence, a future study could look into a similar topic but employing a quantitative method or use various theoretical models or frameworks to look into different research areas in domestic waste management that could further inform and improve the recycling attitudes of Malaysians.

\section{ACKNOWLEDGEMENTS}

The study was made possible with a research grant awarded by the Ministry of Higher Education Malaysia through the FRGS-RACER Grant (600-IRMI/FRGSRACER 5/3 (003/2019). The researchers (authors) would like to thank Universiti Teknologi Mara (UiTM) for managing the research and the Faculty of Architecture, Planning and Surveying, UiTM, for supporting the work. 


\section{REFERENCES}

Abas, M. A. (2014). Municipal Solid Waste Management in Malaysia: An Insight Towards Sustainability. (May). https://doi.org/10.13140/2.1.1774.6246

Aini, M. S., Laily, P., Nurizan, Y., Sharifah Azizah, H., Zuroni, J., \& Norhasmah, S. (2006). Sustainability knowledge, attitude and practices of Malaysians. WIT Transactions on Ecology and the Environment, 93(June), 743-751. https://doi.org/10.2495/SC060711

Ajzen, I. (1991). The theory of planned behaviour. Organisational Behavior and Human Decision Processes, 50(2), 179-211. https://doi.org/10.1016/0749-5978(91)90020-

Ali, N. E., Siong, H. C., Zainol, H., \& Mohd Talmizi, N. (2017). Socio-Demographic Influencing Behaviour against Solid Waste Minimisation in Shah Alam City, Malaysia. Environment-Behaviour Proceedings Journal, 2(6), 53. https://doi.org/10.21834/e-bpj.v2i6.989

Arksey, H., \& O'Malley, L. (2005). Scoping studies: Towards a methodological framework. International Journal of Social Research Methodology: Theory and Practice, 8(1), 19-32. https://doi.org/10.1080/1364557032000119616

Al Mamun, A., Mohiuddin, M., Ahmad, G. Bin, Thurasamy, R., \& Fazal, S. A. (2018). Recycling intention and behaviour among low-income households. Sustainability (Switzerland), 10(7), 1-22. https://doi.org/10.3390/su10072407

Bakar, A. A., Osman, M. M., Bachok, S., Zen, I., \& Abdullah, M. F. (2017). A review on sustainable wellbeing indicators for human interrelationships with the environment. Planning Malaysia, 15(1), 357-368. https://doi.org/10.21837/pmjournal.v15.i6.252

Bakar, A. A., Osman, M. M., \& Hitam, M. (2020). Attitudes and pro-environmental behaviours: Determining factor of personality and lifestyle. Planning Malaysia, 18(1), 1-10. https://doi.org/10.21837/pm.v18i11.704

Banerjee, R. (2015). Importance of Recycling. International Journal of Innovative Research in Electrical, Electronics, Instrumentation and Control Engineering, 3(6), 2321-2004. https://doi.org/10.17148/IJIREEICE.2015.3611

Barr, S. (2007). Factors influencing environmental attitudes and behaviours: A U.K. case study of household waste management. In Environment and Behavior (Vol. 39). https://doi.org/10.1177/0013916505283421

Becker, N., \& Lindhqvist, T. (2014). Increasing High Recycling Rates Management Supervisors. (September). https://doi.org/10.13140/RG.2.2.29133.33769

Chen, B., \& Lee, J. (2020). Household waste separation intention and the importance of public policy. International Trade, Politics and Development, 4(1), 61-79. https://doi.org/10.1108/itpd-03-2020-0008

Chu, P. Y., \& Chiu, J. F. (2003). Factors influencing household waste recycling behaviour: Test of an integrated model. Journal of Applied Social Psychology, 33(3), 604-626. https://doi.org/10.1111/j.1559-1816.2003.tb01915

du Toit, J., Wagner, C., \& Fletcher, L. (2017). Socio-spatial factors are affecting household recycling in townhouses in Pretoria, South Africa. Sustainability (Switzerland), 9(11). https://doi.org/10.3390/su9112033

Eusuf, M. A., Ibrahim, M., Shamzani Affendy, M. D., \& Islam, R. (2011). Solid waste generation characteristics: The Malaysian local authorities' outlook. Planning 
Nurul Rif'ah Afiqah Abd Rauf, Hamizah Yakob, Yusfida Ayu Abdullah, Oliver Ling Hoon Leh, Marlyana Azyyati Marzukhi and Raja Norashekin Raja Othman

Exploring the Theory Planned Behaviour to Derive the Factors of Human Behaviour for Domestic Waste Recycling

Malaysia, 9(November 2011), 51-76. https://doi.org/10.21837/pmjournal.v9.i2.85

Fauziah, S. H., \& Agamuthu, P. (2012). Trends in sustainable landfilling in Malaysia, a developing country. Waste Management and Research, 30(7), 656-663. https://doi.org/10.1177/0734242X12437564

Jeffrey D. Sachs. (2015). The Age of Sustainable Development. New York, NY: Columbia University Press. 543 pages. DOI: 10.1080/01944363.2015.1077080

Jereme, I., Siwar, C., \& Alam, M. (2015). Waste Recycling in Malaysia: Transition from Developing to Developed Country. Indian Journal of Education and Information Management, 4(1), 1-14-14. https://doi.org/10.31235/osf.io/xgf8k

Karim Ghani, W. A. W. A., Rusli, I. F., Biak, D. R. A., \& Idris, A. (2013). An application of the theory of planned behaviour to study the influencing factors of participation in source separation of food waste. Waste Management, 33(5), 1276-1281. https://doi.org/10.1016/j.wasman.2012.09.019

Khalil, M. S., Ho, Y. M., Manaf, L. A., Sharaai, A. H., \& Nabegu, A. B. (2019). Income perspective on the factors influencing households' recycling intention: Implications from the extended theory of planned behaviour. Planning Malaysia, 17(2), 191-202. https://doi.org/10.21837/pmjournal.v17.i10.640

Knickmeyer, D. (2020). Social factors influencing household waste separation: A literature review on good practices to improve the recycling performance of urban areas. Journal of Cleaner Production, 245, 118605. https://doi.org/10.1016/j.jclepro.2019.118605

Kumar, A. (2019). Exploring young adults' e-waste recycling behaviour using an extended theory of planned behaviour model: A cross-cultural study. Resources, Conservation and Recycling, 141(June 2018), 378-389. https://doi.org/10.1016/j.resconrec.2018.10.013

Miafodzyeva, S., \& Brandt, N. (2013). Recycling behaviour among householders. Synthesising determinants via a meta-analysis. Waste and Biomass Valorisation, 4(2), 221-235. https://doi.org/10.1007/s12649-012-9144-4

Miliute-Plepiene, J., Hage, O., Plepys, A., \& Reipas, A. (2016). What motivates households recycling behaviour in recycling schemes of different maturity? Lessons from Lithuania and Sweden. Resources, Conservation and Recycling, 113, 40-52. https://doi.org/10.1016/j.resconrec.2016.05.008

Mokhtar, Nadiah \& Wan Ishak, Faizal \& Romali, Noor \& Che Osmi, Siti Fatimah \& Abu Samah, Mohd Armi. (2013). Municipal Solid Waste Composition Study of Selected Area in Gambang, Pahang. IOP Conference Series: Earth and Environmental Science. 16. 2041-. 10.1088/1755-1315/16/1/012041.

Ong, C., Fearnley, L., \& Chia, S. B. (2019). Towards a sustainable future: a holistic inquiry of waste management behaviours of Singapore households. International Journal of Sustainable Development and World Ecology, 26(7), 583-596. https://doi.org/10.1080/13504509.2019.1631898

Strydom, W. F. (2018). Applying the theory of planned behaviour to recycling behaviour in South Africa. Recycling, 3(3). https://doi.org/10.3390/recycling3030043

Tabernero, C., Hernández, B., Cuadrado, E., Luque, B., \& Pereira, C. R. (2015). A Multilevel Perspective to Explain Recycling Behaviour in Communities. Journal of Environmental Management, 159, 192-201. 
PLANNING MALAYSIA

Journal of the Malaysia Institute of Planners (2021)

https://doi.org/10.1016/j.jenvman.2015.05.024

Teo, C. B.-C. (2016). Recycling Behaviour of Malaysian Urban Households and Upcycling Prospects. Journal of International Business, Economics and Entrepreneurship, 1(1), 915.

Thomas, C., \& Sharp, V. (2013). Understanding the normalisation of recycling behaviour and its implications for other pro-environmental behaviours: A review of social norms and recycling. Resources, Conservation and Recycling, 79, 11-20. https://doi.org/10.1016/j.resconrec.2013.04.010

Tolinski, M. (2012). Plastics and Sustainability: Towards a Peaceful Coexistence between Bio-based and Fossil Fuel-based Plastics. Journal of Plastic Film \& Sheeting, 28(2), 181-182. https://doi.org/10.1177/8756087912441283

Towolioe, S., Permana, A. S., Aziz, N. A., Ho, C. S., \& Pampanga, D. G. (2016). The Rukun Warga-based $3 R$ s and waste bank as a sustainable solid waste management strategy. Planning Malaysia, 4(Special Issue 4), 181-196.

https://doi.org/10.21837/pmjournal.v14.i4.157

Verdugo, C. V. (2012). The positive psychology of sustainability. Environment, Development and Sustainability, 14(5), 651-666. https://doi.org/10.1007/s10668012-9346-8

Wang, B., Ren, C., Dong, X., Zhang, B., \& Wang, Z. (2019). Determinants shaping willingness towards online recycling behaviour: An empirical study of household e-waste recycling in China. Resources, Conservation and Recycling, 143(January 2019), 218-225. https://doi.org/10.1016/j.resconrec.2019.01.005

Xu, L., Ling, M., Lu, Y., \& Shen, M. (2017). Understanding household waste separation behaviour: Testing the roles of moral, past experience, and perceived policy effectiveness within the theory of planned behaviour. Sustainability (Switzerland), 9(4). https://doi.org/10.3390/su9040625

Received: $18^{\text {th }}$ May 2021. Accepted: $2^{\text {nd }}$ July 2021 